\title{
VIVER EM REDE: UMA ANÁLISE SOBRE AS IMPLICAÇÕES DO USO DAS MÍDIAS SOCIAIS POR ESTUDANTES UNIVERSITÁRIOS
}

\author{
VIVIR EN REDE: UN ANÁLISIS DE LAS IMPLICACIONES DEL USO \\ DE LOS MEDIOS SOCIALES PARA LOS ESTUDIANTES UNIVERSITARIOS
}

\section{LIVING IN NETWORK: AN ANALYSIS OF THE IMPLICATIONS OF THE USE OF SOCIAL MEDIA BY UNIVERSITY STUDENTS}

\author{
Ana Cristina Alves LIMA ${ }^{1}$ \\ Juliene de Cássia LEIVA ${ }^{2}$ \\ Sebastião de Souza LEMES ${ }^{3}$
}

RESUMO: O trabalho buscou analisar e discutir, a partir de uma abordagem predominantemente quantitativa, a repercussão causada pelo uso das mídias sociais na vida de estudantes de uma Universidade situada na cidade de Araraquara (SP). Após a revisão bibliográfica sobre o tema, foi realizada uma pesquisa de campo junto aos estudantes que utilizam mídias sociais como o Facebook, Twiter e Instagram, procurando identificar quais as percepções dos usuários acerca de benefícios e prejuízos devido ao uso. O estudo contou com a participação de 140 discentes do curso de Psicologia, 92 participantes do curso de Biologia e 51 participantes do curso de Engenharia da Computação. Os estudantes responderam a um questionário sobre o tema tratado. O estudo concluiu que a maioria $(95,76 \%)$ dos participantes utiliza as redes sociais frequentemente e afirma que não isto não gera mudanças ou implicações consideráveis em sua vida. Apresentam como benefícios o uso a fim de diminuir a distância física, melhorando sua interação e comunicação, facilidade na troca e obtenção de informações, principalmente na aquisição de conhecimento, na educação e entretenimento. Quanto aos prejuízos causados, indicam exposição excessiva de questões pessoais no cotidiano, dependência do uso da internet na realização de suas atividades e alienação das situações concretas.

PALAVRAS-CHAVE: Mídias sociais. Interação social. Uso de tecnologia. Redes sociais. Educação nas redes sociais.

RESUMEN: El presente trabajo presenta el análisis y discusión de la repercusión causada por las redes sociales en la vida de estudiantes de una Universidad ubicada en la ciudad de Araraquara (SP) a través de un abordaje predominantemente cuantitativo. Tras una revisión bibliográfica sobre el tema, fue realizada una investigación envolviendo un trabajo de campo con los estudiantes que utilizan esas redes como

${ }^{1}$ Universidade Estadual Paulista (Unesp), Araraquara - SP - Brasil. Doutoranda do Programa de Pósgraduação em Educação Escolar. E-mail: anacristina.alveslima@ gmail.com

${ }^{2}$ Universidade Estadual Paulista (Unesp), Araraquara - SP - Brasil. Doutora do Programa de Pósgraduação em Educação Escolar. E-mail: julieneleiva@gmail.com

${ }^{3}$ Universidade Estadual Paulista (Unesp), Araraquara - SP - Brasil. Docente do Programa de PósGraduação em Educação Escolar. E-mail: ss.lemes2@gmail.com 
Facebook, Twitter e Instagram, buscando identificar cuales las percepciones de los usuarios en relación a los beneficios y perjuicios presentes en sus usos. El estudio contó con la participación de 140 discentes del curso de Psicología, 92 participantes del curso de Biología y 51 participantes del curso de Ingeniería en Computación. Los estudiantes respondieron a una encuesta sobre el tema tratado. La investigación concluyó que la mayoría (95,76\%) de los participantes utiliza las redes sociales a menudo afirmando que el uso no genera cambios ni implicaciones considerables en su vida. En relación a los beneficios, señalan que su uso disminuye la distancia física, mejorando su interacción y comunicación con otros usuarios, facilitando el intercambio de informaciones principalmente en la adquisición del conocimiento en la educación y en el entretenimiento. Cuánto a los perjuicios los participantes indican la excesiva exposición de las cuestiones personales en su cotidiano, la adicción a internet para la realización de sus actividades y la alienación de sus situaciones concretas.

PALABRAS-CLAVE: Medios de comunicación social. La interacción social. El uso de la tecnologia. Las redes sociales. La educación a través de las redes sociales.

ABSTRACT: The work sought to analyze and discuss, from a predominantly quantitative approach, the repercussion caused by the use of social media in the life of students of a University located in the city of Araraquara (SP). After the bibliographic review on the subject, a field research was carried out with students who use social media such as Facebook, Twiter and Instagram, trying to identify the perceptions of users about benefits and damages due to the use. The study counted on the participation of 140 students of the Psychology course, 92 participants of the Biology course and 51 participants of the course of Computer Engineering. The students answered a questionnaire on the subject. The study found that most (95.76\%) of the participants use social networks often and say that this does not lead to significant changes or implications in their lives. They present as benefits the use in order to reduce the physical distance, improving their interaction and communication, ease in the exchange and obtaining of information, mainly in the acquisition of knowledge, education and entertainment. As for the damages caused, they indicate excessive exposure of personal issues in daily life, dependence on the use of the Internet in carrying out its activities and alienation from concrete situations.

KEYWORDS: Social media. Social interaction. Use of technology. Social networks. Education in social networks.

\section{Introdução}

O presente artigo baseou-se em parte de um Trabalho de Conclusão de Curso desenvolvido no contexto da graduação em Psicologia, no qual destacou-se a relevância e pertinência da discussão sobre a percepção das implicações do uso das mídias sociais para os estudantes universitários ${ }^{4}$.

${ }^{4}$ SILVA, M. de F. C da.; GOMES, M. A.; CARVALHO, V. Viver em rede: uma análise sobre as implicações do uso das mídias sociais. 
O estudo acerca das relações humanas na atualidade deve considerar, entre as possibilidades de configuração em que se apresentam aquelas que se estabelecem e se mantêm graças à mediação da tecnologia. Os desdobramentos proporcionados pela presença dos recursos tecnológicos enquanto ferramentas que potencializam a interação entre as pessoas deveriam tornar-se objeto de reflexão, dado seu potencial de transformação (PINTO, 2005).

Nesse contexto, encontra-se uma nova forma de compreender o funcionamento do mundo, lidar com as informações que são disponibilizadas muito rapidamente, e especialmente produzir conhecimento (LÉVY, 1999). O uso que se faz das informações encontradas em ambientes virtuais para tanto vem a ser uma das principais preocupações de estudiosos voltados para a interface das áreas de estudo da Educação e da Tecnologia, tendo em vista o desenvolvimento científico (PINHEIRO, 2003).

Com base nessas breves considerações iniciais, o presente trabalho está voltado para a investigação acerca das implicações do uso de redes sociais mediadas por computadores, aqui chamadas de mídias sociais, sobre a vida dos seus usuários.

Autores como Tomaél, Alcará e Chiara (2005) definem o uso de mídias sociais como uma das estratégias adotadas pela sociedade para o compartilhamento da informação e do conhecimento, mediante as relações entre os atores que as integram.

Segundo Dias e Couto (2011), as mídias sociais são ambientes virtuais nos quais sujeitos se relacionam instituindo uma forma de sociabilidade que está ligada à própria formulação e circulação do conhecimento. A sociabilidade nas mídias sociais, como o 'Instagram', 'Facebook' e 'Twitter', não tem as mesmas condições de produção que a sociabilidade em espaços escolares ou universitários tradicionais, por exemplo, e essa é uma diferença importante para compreender a divulgação de conhecimento e sua impregnação nos discursos na sociedade contemporânea.

No caso do 'Facebook', isso ocorre pela possibilidade de colocar em circulação e compartilhar textos, artigos, vídeos, eventos, lançamentos de livros, campanhas, etc. No 'Instagram', está ligado ao compartilhamento de fotos e, no 'Twitter', através do recurso de compartilhamento de links.

Para os autores, os enunciados que marcam a entrada do sujeito nessas redes sociais é o "tudo visto", que está no cerne das mídias citadas. O sujeito que não se diz nesse espaço, que não "cutuca", não “curte", não “comenta” e não "twitta” os acontecimentos passa a não existir nesse 'ciber' espaço (DIAS; COUTO, 2011). 
Com a expansão dos meios de comunicação interpessoal pela internet, cada vez mais as mídias sociais passaram a atender as necessidades que os indivíduos têm de se comunicar, se exibir e se relacionar (SHIMAZAKI; PINTO, 2011).

O contínuo avanço tecnológico permite, cada vez mais, facilidade de acesso à internet, através de diferentes dispositivos, como aparelhos celulares, 'notebooks', 'tablets', 'ipad', 'iphone' e outros. Esses suportes permitem ao usuário a conexão com a internet a qualquer hora e em qualquer lugar, tornando mais intensa a relação que se estabelece entre tecnologia e comunicação (DOMINSKI, 2013 apud EISENKRAEMER, 2006).

Tomaél e Marteleto (2013) dizem que a interação é própria da sociedade e ela ocorre por meio da reciprocidade entre os indivíduos. É fato que os indivíduos gostam de compartilhar o que fazem, o que "curtem", o que estão pensando. Aparentemente trata-se de uma necessidade a ser satisfeita, envolvendo o compartilhamento de preferências.

As mídias sociais podem ser usadas para diferentes funções, como para conversar, se apresentar, expressar suas atividades cotidianas, começar novas amizades, procurar trabalho ou lugares para viajar, comprar e compartilhar coisas de interesses comuns a outras pessoas e, muitas vezes, também compartilham conhecimentos científicos, pensamentos críticos ou espontâneos, agrupam-se para obter maior influência em suas ideias e propósitos (MARQUES et al,2013).

Em seus estudos, Martins et al (2009, p.52) dizem que:

De modo geral, a percepção que se tem sobre as redes sociais é um tanto negativa, já que são apontadas, apenas, como meios de distração, onde os estudantes estariam perdendo horas do seu dia, que poderiam estar sendo aproveitadas para estudar e aprender, navegando em páginas virtuais que não agregam nenhum valor à construção do conhecimento.

Os mesmos autores contestam esta percepção, quando dizem que os sistemas de ensino devem se adaptar para poder contemplar esta poderosa mídia, que já é adotada por estudantes de todas as classes sociais. Nesse contexto, destaca-se que "a aprendizagem não é uma atividade simplesmente individual, ela precisa da colaboração e o intercâmbio entre indivíduos. A vida coletiva é indispensável para o desenvolvimento humano" (PIAGET, 2002 apud MARTINS et al, 2009, p. 54).

As mídias sociais, principalmente o 'Facebook', devido seu alcance e facilidade de acesso, oferecem uma base de interação gratuita, com recursos extremamente 
funcionais que são relevantes para o uso dessa rede como ferramenta de ensino, permitindo a troca de informações em tempo real (FUMIAN; RODRIGUES, 2013).

Marchioli et al (2011) apontam que lidamos com uma realidade na qual o excesso de informação, a utilização da mídia como ferramenta de ensino e a priorização da imagem em detrimento da imaginação, está mudando o foco de atenção dos estudantes. É comum vermos as pessoas dividindo a atenção entre a tela do computador ou do celular e qualquer outra atividade que estejam fazendo no mesmo momento (BARBOSA, 2013).

Analisando por outro ângulo, Hubbe e Blumenthal (2013) afirmam que o uso das mídias sociais apresenta seu lado negativo, que parte do processo de comunicação, que inclui o tempo gasto em interações sociais, implicando na diminuição do tempo nas relações familiares e instituições sociais, abrangendo desde a família até a escola. Para eles, há o aumento de conflitos sociais e interculturais, aumento no desentendimento entre indivíduos, grupos e organizações, além do aumento de pessoas com pouca habilidade para se comunicar efetivamente através da fala e da escrita.

A necessidade e demanda pela comunicação veloz e pela eficiência em termos de tempo, tem limitado não apenas a comunicação em grupos sociais, mas também tem “contraído" a linguagem e modos de falar. O advento das mensagens instantâneas contribuiu para a comunicação não efetiva, com novas gírias e maneiras corrompidas de falar.

Em seus estudos, Barbosa (2013) apresenta considerações sobre o entendimento de que, na conversa real (com presença física), não se controla o que se diz. A conversa escrita nos permite um maior domínio de nós mesmos; a tecnologia possibilita, portanto, lapidar as relações. Estar conectado 24 horas dá a sensação de estar acompanhado por olhos e ouvidos. No entanto, esse acompanhamento virtual nos passa a ideia de que sempre seremos ouvidos e que nunca estaremos sós.

A ideia de esquiva da solidão pode ser benéfica no mundo contemporâneo, no qual as configurações familiares e sociais não fornecem tanta companhia e apoio, mas, no entanto, estar sempre "acompanhado" faz com que a solidão passe a ser vista e sentida com pavor, contra o qual é necessário lutar (BARBOSA, 2013 apud TURKLE, 2012).

Com relação ao consumo de produtos que veiculam dentro das páginas das mídias sociais, Gil (2012) diz que as instituições estão trabalhando cada vez mais a sua imagem e marca para deixá-los com mais personalidade, se posicionando e 
apresentando uma comunicação feita de forma genuína e clara, atendendo aos interesses dos usuários.

"A nossa sociedade se expressa como a sociedade do consumo, ela dita padrões do que é 'belo', do que é 'bom' e do que se deve ter para ser feliz". Nessa nova configuração, ou o indivíduo se satisfaz obtendo o objeto de desejo ou ele se realiza em somatizações como depressão e estresse (BARBOSA, 2013, p. 45).

Tendo em vista a crescente mudança na forma de interação e relacionamento social, em função do uso das mídias sociais como 'Facebook', 'Instagram' e 'Twitter'. O estudo desse tema se mostra pertinente, no contexto da Psicologia, dada a necessidade de reflexão acerca de suas influências sobre o comportamento humano na atualidade.

Ainda que se evidencie a pertinência do estudo em questão, nota-se a existência de uma lacuna considerável a esse respeito na literatura científica, relacionada ao fato de que o fenômeno da interação em redes sociais mediadas pelo computador foi estabelecido e se intensificou recentemente. Assim, a proposta do presente trabalho pretende contribuir para a produção de conhecimento sobre o tema, reunindo elementos que possam enriquecer o debate sobre as influências positivas e negativas do uso das mídias sociais no cotidiano das pessoas, e mais particularmente entre estudantes universitários.

\section{Objetivo}

Analisar a percepção dos participantes acerca das influências positivas e negativas das mídias sociais em suas vidas.

\section{Método}

O presente estudo teve como participantes alunos regularmente matriculados nos cursos noturnos de Psicologia, Biologia e Engenharia da Computação do Centro Universitário de Araraquara $^{5}$ - Uniara, totalizando 283 participantes, abrangendo todos os anos dos cursos. Essa amostra foi selecionada de acordo com a disponibilidade dos estudantes consultados pelas pesquisadoras, na sala de aula em que se encontravam.

Foi utilizado como instrumento para a pesquisa um questionário, tendo em vista a caracterização da amostra, considerando dados sobre idade, sexo, renda familiar,

${ }^{5}$ A partir do ano de 2016, a instituição passou a ser Universidade. 
dados sobre gasto de tempo e tipo de acesso às mídias sociais, para a compreensão de possíveis implicações do uso das mídias sociais. Após as aplicações, os dados obtidos foram submetidos à análise quantitativa, sendo realizada de acordo com a proposta do questionário, articulando-se os conceitos encontrados na literatura sobre o tema. Anteriormente ao início da coleta de dados junto aos participantes da pesquisa, o projeto foi submetido à aprovação do Comitê de Ética em Pesquisa do Centro Universitário de Araraquara - Uniara (CAAE 25371513.0.0000.5383).

\section{Resultados e discussão}

A pesquisa contou com 283 participantes, 110 homens e 30 mulheres do curso de Psicologia; 60 mulheres e 32 homens do curso de Biologia e 43 homens e 8 mulheres do curso de Engenharia da Computação.

Nota-se nos cursos de Psicologia e Biologia a predominância de indivíduos do sexo feminino, sendo o curso de Psicologia caracterizado por 78,57\% de mulheres e $21,43 \%$ de homens e o curso de Biologia $65,22 \%$ de mulheres e $34,78 \%$ de homens. No curso de Engenharia da Computação há predominância de indivíduos do sexo masculino, sendo constituído por $84,31 \%$ de homens e $15,09 \%$ de mulheres.

Quanto à faixa etária dos participantes da pesquisa, no curso de Psicologia os alunos possuem entre 18 e 60 anos. Notou-se que no curso de Biologia, assim como no de Engenharia, a faixa etária é mais baixa, ficando entre 18 e 50 anos e 18 e 40 anos respectivamente. É importante destacar que a faixa etária predominante nos três cursos foi dos 21 aos 30 anos, o que é caracterizado por 57,14\% no curso de Psicologia, $51,09 \%$ no curso de Biologia e 66,67\% no curso de Engenharia da Computação.

Os dados do perfil dos participantes mostraram maior participação do sexo feminino, devido a existir um maior numero de mulheres matriculadas nos cursos de Psicologia, com $(78,56 \%)$, e Biologia $(65,21 \%)$, enquanto na Engenharia da Computação a predominância é do sexo masculino (84,31\%). Quanto à idade dos participantes, em todos os cursos resulta uma média maior de universitários com idade de 21 a 30 anos, sendo que não há estudantes acima de 61 anos. Quanto à renda familiar dos participantes, a grande maioria encontra-se nas categorias entre 1 a 3 salários mínimos (de R \$ 678,01 até R \$ 2.034,00), 104 participantes, e de 3 a 6 salários mínimos (de $\mathrm{R} \$ 2.034,01$ até $\mathrm{R} \$ 4.068,00), 101$ participantes. 
Portanto, os resultados indicam um perfil de universitários jovens, predominantemente feminino, em relação ao qual verifica-se uma consistência com os indicadores do Instituto Brasileiro de Geografia e Estatística (IBGE, 2008a, 2008b). Em síntese publicada no ano de 2008, existe um predomínio de mulheres ocupando os bancos escolares universitários. É interessante ressaltar ainda que segundo o relatório do ministério de planejamento (BRASIL, 2012), ocorreu avanço no campo da educação, com aumento de jovens inseridos na formação superior. As faixas etárias de 18 a 20 anos e de 21 a 30 anos são mais frequentes que a faixa etária acima de 30 anos, que tem menor representatividade, demostrando que a maior parte dos estudantes é constituída por jovens de classe média.

Quanto à participação dos indivíduos em redes sociais, nota-se que a grande maioria é usuária. No curso de Psicologia 94,29\%, em Biologia 95,65\% e em Engenharia da Computação 100\% dos participantes. Questionados quanto à motivação para não utilizarem as redes sociais, os participantes apresentaram duas respostas diferentes. A maioria, 12 indivíduos, disse que não sente necessidade de participar, sendo 8 alunos de Psicologia (100\% dos participantes que responderam à pergunta) e 4 de Biologia ( $80 \%$ dos participantes que responderam a esse item) e apenas 1 participante (20\% dos participantes que responderam a essa pergunta) do curso de Biologia disse que não participa por ser contrário às redes sociais.

Foi encontrada lacuna na literatura científica em relação a essa questão, ainda que haja ênfase na utilização das redes sociais, não se tem procurado saber os motivos de uma parcela da população recusar-se a utilizar essa tecnologia. Observa-se a inserção no 'Facebook' é que aparece com maior frequência, sendo 55,74\% do curso de Psicologia, 55,06\% de Biologia e 52,13\% do curso de Engenharia da Computação.

Segundo Lisboa et al. (2012), apesar do 'Facebook' ter sido criado em 2004 apenas e em 2006 seu cadastro ter sido liberado para qualquer internauta, teve um crescimento surpreendente desde então. O 'Facebook' ainda é líder em número de acessos, obtendo 66,54\% em detrimento a outras redes sociais. Enquanto isso o 'Twitter' possui apenas 1,75\% dessa fatia (TRINDADE; HUTTNER, 2013).

Esses dados corroboram com os resultados obtidos na presente pesquisa, em que se obteve a frequência de inserção nessa rede social como a mais alta entre todas as consideradas. Frente à questão sobre em que equipamento faz uso das mídias sociais, a resposta é que ocorre com mais frequência através de celular. No curso de Psicologia 
são $36,63 \%$, em Biologia 36,41\% e no curso de Engenharia a frequência foi a mesma tanto para o item celular quanto o equipamento 'notebook', 32,41\%.

Trindade e Huttner (2013) afirmam, segundo pesquisa realizada sobre os hábitos dos brasileiros na internet, que 53\% dos indivíduos pesquisados navegam no 'ciberespaço' através de celulares, sendo que 98\% afirmam utilizar para acessar as redes sociais. Os dados deste estudo corroboram tal pesquisa, pois encontrou como informação relevante o fato de que a maior frequência de respostas foi quanto à utilização de mídias sociais pelo celular. Isto se deve principalmente à sua portabilidade e facilidade de acesso.

Na questão sobre em que ambiente isso ocorre, analisa-se que a utilização das redes sociais ocorre com mais frequência em casa. No curso de Psicologia a incidência é de 35,33 \%, em Biologia 32,82\% e em Engenharia da Computação é de 32,90\%. O item "em trânsito" é o que menos foi escolhido, sendo sua frequência de 8,70\%, 8,02\% e 5,81\% respectivamente. Como afirma Barbosa (2013), as redes sociais estão presentes constantemente nas atividades cotidianas dos indivíduos. Seja em restaurantes, cinema, bares, entre amigos, na sala de análise, pode-se ver pessoas conectadas.

No questionamento referente à frequência de utilização das mídias sociais, a resposta que obteve maior incidência foi "frequentemente". No curso de Psicologia esse item foi escolhido por 43,18\% dos participantes, no curso de Biologia 42,05\% e no de Engenharia da Computação 41,18\%. Nota-se que o item menos escolhido também pelos três cursos foi "raramente", com incidência de 5,30\%, 1,14\% e 11,76\%, respectivamente. Apesar da utilização de redes sociais se dar com maior frequência, segundo o estudo, em casa, a utilização de aparelhos celulares possibilitou abranger outros espaços. Trindade e Hutt (2013) afirmam que o celular possibilita, através da conexão $3 \mathrm{G}$ ou $4 \mathrm{G}$, a indivíduos que moram em regiões com acessos tradicionais precários ou ausentes se conectarem.

Em relação à questão de quanto tempo é dedicado às mídias sociais por dia, a resposta mais frequente foi de 1 a 3 horas nos três cursos, sendo o item respondido por $35,61 \%$ dos entrevistados do curso de Psicologia, 31,82\% do curso de Biologia e 45,10\% do curso de Engenharia da Computação. Em outro item do questionário, perguntou-se qual a finalidade da utilização das mídias para os indivíduos pesquisados. A resposta que obteve maior frequência foi "contato com amigos" seguido de “entretenimento". No curso de Psicologia obteve-se 22,48\% e 20,00\%, no curso de 
Biologia 21,88\% e 20,31\% e no curso de Engenharia da Computação 22,07\% e 21,13\% respectivamente.

Gallardo (2014) afirma que através das novas tecnologias da internet, encontros transnacionais ocorrem com maior frequência, possibilitando comunicação e troca de experiências de forma mais dinâmica, além de encurtar distâncias geográficas. Trindade e Huttner (2013) afirmam que o elemento mais importante de uma rede social é o capital social. Lisboa et al (2012) acrescentam que ela veio para proporcionar meios diferentes e interessantes de interação. Ele compara o 'Facebook' ao ato de ficar sentado na porta de casa, nas cidades do interior, num ritual diário de convivência, onde conversamos com pessoas que conhecemos e reforçamos os laços de amizade.

Dos questionamentos sobre a utilização das mídias sociais avaliados nesta pesquisa, o item "contato com amigos" foi o que obteve maior frequência de respostas, corroborando com as análises acima, em que se discute a diminuição das distâncias geográficas e a importância dada à interação entre os indivíduos. Foi questionado se os participantes já haviam comprado em sites que faziam propaganda em mídias sociais, a resposta que teve mais incidência foi "não". No curso de Psicologia foi o item mais escolhido por $56,06 \%$ dos participantes, no curso de Biologia 54,55\% e no de Engenharia da Computação 66,67\%.

Apesar de ter sido encontrado um artigo publicado por Barbosa (2013), em que ele afirma que hoje o 'Facebook' é o maior agregador de informação de marketing global, por ter seu conteúdo gerado pelo próprio usuário, os dados encontrados pela pesquisa apontam que a maior parte dos participantes não fazem compras em sites que fazem propaganda nas mídias sociais, sendo o 'Facebook' apontado pelos pesquisados como o de maior inserção.

Em relação às questões se os entrevistados haviam sofrido algum prejuízo ligado ao uso das mídias sociais e sendo afirmativa a resposta, qual o tipo, como resultado mostra nas Figuras 12 e 13 a grande maioria dos entrevistados disse não ter sofrido nenhum tipo de prejuízo devido à participação nas mídias sociais. A incidência dessa resposta foi de 74,24\% no curso de Psicologia, 81,82\% no curso de Biologia e 82,35\% no curso de Engenharia da Computação. Quanto aos indivíduos que responderam que tiveram algum tipo de prejuízo, a resposta com maior incidência nos três cursos foi "nas relações pessoais", o item foi o mais escolhido por 60,98\% dos entrevistados no curso de Psicologia, 57,14\% no curso de Biologia e 38,46\% no curso de Engenharia da Computação. 
Foi questionado se os participantes da pesquisa já haviam deixado de se alimentar se haviam se alimentado diante do computador ou celular, acessando as mídias sociais. A resposta que obteve maior incidência nos cursos de Psicologia e Biologia foi "não", sendo o item mais escolhido por 59,85\% e 56,82\% dos participantes respectivamente. No curso de Engenharia da Computação a resposta que obteve maior incidência também foi "não", sendo o item mais escolhido por $54,90 \%$ dos participantes.

Marcos (2011), assim como Silva e Vizzotto (2013), perguntaram aos participantes de sua pesquisa se os mesmos já haviam se privado de necessidades fisiológicas (sono, alimentação, urinar ou defecar) para manter-se mais tempo utilizando tecnologia. Em sua análise de dados, Marcos obteve $38 \%$ de respostas positivas, enquanto Silva e Vizzotto (2013) obtiveram 39,5\% de respostas positivas. Os números encontrados no presente estudo também foram altos e representaram mais de $50 \%$ das respostas positivas nos cursos de Psicologia e Biologia, se sobressaindo às respostas negativas. No curso de Engenharia da Computação a resposta "Não" obteve maior frequência, mas a reposta "Sim" apresenta grande representatividade, com 45,10\% das respostas. Nos três estudos, é preocupante contatar o grande número de participantes que se privam ou realizam de forma errada as necessidades fisiológicas, como é o caso de se alimentar, diante do computador ou celular, acessando as mídias sociais.

Já na relação de atrasos em compromissos por conta de acesso às mídias sociais, o maior resultado é de que não deixam de sair ou comparecer a compromissos agendados para ficarem conectados às mídias sociais, sendo, portanto, o item "não" como o mais escolhido nos três cursos. Em Psicologia foi a resposta de 89,39\% dos indivíduos, em Biologia 92,05\% e em Engenharia da Computação 96,08\%.

Os autores Silva e Vizzotto (2013), em sua pesquisa, analisaram o tema com o seguinte questionamento: Prefere passar mais tempo utilizando tecnologia que estar com seus amigos e familiares? Obtiveram 32,5\% de respostas positivas e $67,5 \%$ de respostas negativas. Em outra pesquisa, Marcos (2011) obteve 7\% de respostas positivas para a mesma pergunta. As duas pesquisas apresentam que a maioria dos participantes preferem a companhia da família / amigos a ficar conectado às mídias sociais, estes resultados condizem com os dados encontrados pela presente pesquisa. Foi ainda questionado se os entrevistados alteram compromissos para ficarem conectados às mídias sociais. O item que obteve maior incidência de resposta foi "nunca". Esta foi a alternativa escolhida por $92,42 \%$ dos participantes do curso de Psicologia, 92,05\% do 
curso de Biologia e 92,16\% do curso de Engenharia da Computação. Importante observar que o item "frequentemente" não apareceu como resposta nos três cursos.

Perguntou-se também se os participantes já haviam se atrasado para algum compromisso devido ao uso das mídias sociais. A resposta com mais incidência nos três cursos foi "não", aparecendo como resposta de 73,48\% dos entrevistados no curso de Psicologia, 70,45\% no curso de Biologia e 82,35\% no curso de Engenharia da Computação. No estudo de Marcos (2011) a análise se deu partir da pergunta: "Costuma descuidar de tarefas escolares, domésticas ou trabalho para permanecer mais tempo utilizando tecnologia?", para a qual obteve $29 \%$ de respostas afirmativas.

Em outro estudo, realizado por Silva e Vizzotto (2013), em que abordam a mesma pergunta, o número de respostas afirmativas foi de 42,5\%. Esses números estão muito elevados com relação aos dados obtidos pela presente pesquisa, já que a alternativa "Nunca" aparece em aproximadamente 92\% das respostas, nos três cursos analisados. A alternativa "Não" foi a que apresentou maior frequência em todos os cursos. Diante do questionamento quanto a compartilharem nas mídias sociais informações do cotidiano, a resposta que obteve maior incidência foi "raramente". A alternativa mais escolhida por 56,06\% dos participantes do curso de Psicologia, 52,27\% do curso de Biologia e 60,78\% do curso de Engenharia da Computação.

Conforme estudo de Espada (2012), falar sobre si mesmo libera dopamina, um hormônio relacionado à sensação de prazer e satisfação. Nesse mesmo estudo encontraram-se dados interessantes quanto à exposição da vida pessoal. Enquanto nas vias tradicionais de relacionamento as pessoas dedicam 30 a $40 \%$ de seu discurso para se auto-promover, nas mídias sociais esse índice é surpreendente, chega a 80\%. Os dados encontrados na presente pesquisa seguem uma via contrária a esse estudo. Indicam que a maior parte dos participantes raramente compartilha informações pessoais nas mídias sociais.

No levantamento sobre a percepção dos entrevistados diante do uso das mídias sociais, a alternativa que obteve maior quantidade de resposta foi "faz bem", sendo a escolha de 61,36\% dos participantes do curso de Psicologia, 54,55\% do curso de Biologia e 49,02\% do curso de Engenharia da Computação. Observando os dados junto a uma pesquisa realizada pela IBA, em parceria com a empresa 'comScore', especializada em pesquisa de mercado, ressalta-se que a internet é o meio de comunicação considerado como o mais importante pelos entrevistados. Essa mesma pesquisa encontrou como dado que $82 \%$ dos brasileiros consideram a internet essencial 
à sobrevivência. As redes sociais são as grandes responsáveis por essas mudanças (ESPADA, 2012). É interessante observar que houve divergência nos resultados encontrados na presente pesquisa, pois o item que obteve maior frequência de respostas

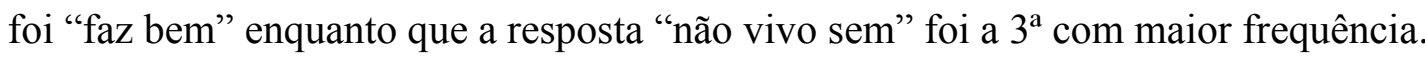

Quanto à relação com as pessoas que integram a rede social, verificou-se que 80,30\% dos entrevistados do curso de Psicologia, 76,14\% do curso de Biologia e 68,63\% do curso de Engenharia da Computação conhecem pessoalmente a maioria das pessoas que fazem parte de sua mídia social. Para essa questão não foi encontrado embasamento teórico, pois os artigos analisados apresentavam os benefícios das mídias sociais para interação, porém não especificavam ou relacionavam sobre as pessoas que o indivíduo conhece pessoalmente, já que grande parte dos indivíduos pesquisados conhece a maioria das pessoas inseridas em sua rede.

Quando questionados sobre a atividade favorita, quando não estavam conectados às mídias sociais, a alternativa que obteve maior incidência de resposta nos cursos de psicologia e biologia foi "passear", $28,70 \%$ e $30,90 \%$ respectivamente. No curso de engenharia da computação a resposta mais escolhida foi "assistir televisão", 24,76\% dos entrevistados.

Quando questionados sobre qual o maior benefício para os usuários das mídias sociais, os participantes dos cursos de Psicologia e de Biologia, indicaram, em sua maioria que é a obtenção de informações o maior fator benéfico. Nesse contexto, essa resposta corrobora com a colocação de LÉVY (2009) quando este diz que as pessoas buscam uma nova forma de compreender o funcionamento do mundo, lidando com as informações que são disponibilizadas muito rapidamente.

A segunda resposta mais frequente, também nos dois cursos, é o contato com várias pessoas, e, a terceira resposta mais indicada foi a facilidade de comunicação para os participantes dos três cursos pesquisados. Essas respostas confirmam o que diz a literatura pesquisada: com o passar do tempo e com a expansão dos meios de comunicação interpessoal pela internet, cada vez mais as mídias sociais passaram a atender as necessidades que os indivíduos têm de se comunicarem, se exibirem e se relacionarem (SHIMAZAKI; PINTO, 2011). Curiosamente, o entretenimento como um benefício, foi a quarta resposta mais frequente nos cursos de Psicologia, Biologia e Engenharia da Computação. Apenas os participantes do curso de Engenharia da Computação (quase 6\%), disseram não atribuir nenhum valor ao uso das mídias sociais. 
Talvez esses pequenos grupos, concordem com a visão de Martins et al (2009, p. 62) quando dizem que:

De modo geral, a percepção que se tem sobre as redes sociais é um tanto negativa, já que são apontadas, apenas, como meios de distração, onde os estudantes estariam perdendo horas do seu dia, que poderiam estar sendo aproveitadas para estudar e aprender, navegando em páginas virtuais que não agregam nenhum valor à construção do conhecimento.

Neste último curso, a resposta com maior frequência foi o benefício de se ter contato com várias pessoas seguida da segunda maior frequência de respostas que indicou a obtenção de informação como benefício. Como já explicitado, essas questões vão ao encontro da visão de Tomaél e Marteleto (2013), quando dizem que a interação é própria da sociedade, e ela ocorre por meio da reciprocidade entre os indivíduos. Aparentemente trata-se de uma necessidade a ser satisfeita, envolvendo o compartilhamento de preferências.

Quando os participantes tiveram que indicar qual o maior risco ou prejuízo para os usuários das mídias sociais, a maioria, dos cursos de Psicologia e de Biologia responderam que perder dinheiro é o maior risco/prejuízo. Essa indicativa corrobora com a colocação de Gil (2012) quando esta diz que as instituições trabalham cada vez mais a sua imagem e marca para deixá-los com mais personalidade para atender aos interesses dos usuários. Assim, a autora confirma que as empresas, através das mídias sociais, têm sim o "poder" de fazer com que os usuários gastem dinheiro. Portanto, parafraseando Barbosa (2013), a nossa sociedade dita padrões de beleza que são veiculados e potencializados pelas mídias sociais, levando o indivíduo a gastar para se satisfazer.

No curso de Engenharia da Computação o maior risco/prejuízo é a falta de privacidade/exposição excessiva. Essa resposta foi a segunda mais indicada pelos universitários dos cursos de Psicologia e de Biologia. Esses números contestam as colocações de Barbosa (2013 apud TURKLE, 2012), que diz que esse acompanhamento virtual nos passa a ideia de que sempre seremos ouvidos e que nunca estaremos sós. Estar sempre "acompanhado" faz com que a solidão passe a ser vista e sentida com pavor, contra o qual se tem que lutar; o que os números indicam é que, para essa amostra, estar sozinho não se qualifica como pavoroso, é necessário ter seu espaço, para ficar sozinho consigo mesmo. 
Já a segunda resposta mais indicada no curso de Engenharia da Computação é o receio de que o uso se torne um vício, essa mesma resposta foi a terceira mais apontada pelos participantes dos cursos de Psicologia e de Biologia. Neste aspecto, a literatura vigente não apresentou estudos relacionados a respeito. Quanto ao distanciamento das relações reais, os integrantes do curso de Engenharia foram os que mais apontaram essa questão como o quarto risco/prejuízo. Assim, eles concordam com Hubbe e Blumenthal (2013), pois esses autores afirmam que o uso das mídias sociais apresenta seu lado negativo, que parte do processo de comunicação, que inclui o tempo gasto em interações sociais, implicando na diminuição do tempo nas relações familiares e instituições sociais, abrangendo a família até a escola. Ao mesmo tempo, essa mesma frequência $(11,11 \%)$ deixou de responder a esta questão, o que sugere que essa amostra não vê riscos/prejuízos no uso das mídias sociais.

\section{Considerações finais}

O estudo concluiu que a maioria $(95,76 \%)$ dos participantes utiliza as redes sociais frequentemente e afirma que isto não gera mudanças ou implicações consideráveis em suas vidas. Apresentam como benefícios do uso dessas redes a diminuição da distância física, melhorando sua interação e comunicação, a facilidade na troca e obtenção de informações, principalmente na aquisição de conhecimento, na educação e entretenimento. Quanto aos prejuízos causados, indicam exposição excessiva de questões pessoais no cotidiano, o receio de se tornarem dependentes do uso das mídias, além de terem perdas financeiras. Com relação às dificuldades encontradas durante a pesquisa, apesar de ter sido considerado devidamente na análise dos dados, destacou-se a devolução de questionários não respondidos pelos participantes.

Por fim, é indiscutível e redundante dizer que as mídias sociais vêm a cada dia mais, facilitando a vida das pessoas. Sendo assim, se faz necessária a adaptação da Universidade, no que tange ao processo de ensino/aprendizagem, frente às novas formas de interação possíveis entre discentes e docentes. Esta pesquisa corrobora com a literatura encontrada, tanto no âmbito dos aspectos positivos como dos aspectos negativos das implicações das mídias sociais na vida das pessoas.

\section{REFERÊNCIAS}


BARBOSA, M. K. Viver conectado, subjetividade no mundo contemporâneo IDE. São Paulo, 35 [55], janeiro 2013.

DIAS, C.; COUTO, F. O. As redes sociais na divulgação e formação do sujeito do conhecimento: compartilhamento e produção através da circulação de ideias

Linguagem em (Dis)curso, Tubarão, SC, v. 11, n. 3, p. 631-648, set./dez. 2011.

DOMINSKI, D. K.; BRITO, D. E. N.; SANTOS, I. N.; RODRIGUES, J. A.; MOURA, E.; LOPES, R. M. F.; ESTEVES, C. S. Reflexões sobre a tecnologia e adolescentes: mitos e verdades. Id on line Revista de Psicologia. Ano 7, n. 20, Julho/2013 - ISSN 1981-1179.

FUMIAN, A. M.; RODRIGUES, D. C. G. A. O facebook enquanto plataforma de ensino. Revista Brasileira de Ensino de C\&T, v. 6, n. 2 ISSN - 1982-873X, mai-ago. 2013.

GIL D. Uso corporativo das redes sociais digitais: o Twitter no Banrisul - Porto Alegre, 2012.

HUBBE, G. B. B.; BLUMENTHAL, M. Tecnologia da comunicação e o risco à sociedade - UFSC - EMC 5003 - tecnologia \& desenvolvimento - 2013. Id On Line Revista de Psicologia, v.7, n. 20, 2013.

LÉVY, P. Cibercultura. Rio de Janeiro: Editora 34, 1999.

MARCHIORI, L. L. M.; MELO, J. J.; MELO, W. J. Avaliação docente em relação às novas tecnologias para a didática e atenção no ensino superior. Avaliação, Campinas; Sorocaba, SP, v. 16, n. 2, p. 433-443, jul. 2011.

MARQUES, R. S. R.; JACOBSEN, A. L.; COSTA, A. M.; BUNN, D. A.; MEIRA, S. L.; TESSARO, A. C. As redes sociais da internet e a gestão do conhecimento em ead. $\mathbf{X}$ Congresso Brasileiro de Ensino Superior a Distância. Belém/PA: UNIREDE, 11-13 de junho de 2013.

MARTINS, G. J. T.; MARTINEZ, G. A. D. P.; FILHO, S. S. L.; PEREIRA, M. F. A contribuição das redes sociais virtuais para a aprendizagem e construção do conhecimento: evidências em estudantes de cursos de graduação. IX Colóquio Internacional sobre Gestão Universitária na América do Sul. Florianópolis-Brasil 25 a 27 de novembro de 2009.

PINHEIRO, L. V. R. Comunidades cientificas e infra-estrutura tecnológica no Brasil para uso de recursos eletrônicos de comunicação e informação na pesquisa. Ci. Inf., Brasília, v. 32, n. 3, p. 62-73, set./dez. 2003.

PINTO, A. V. O conceito de tecnologia. Rio de Janeiro: Contraponto,v.1 e 2. 2005.

SHIMAZAKI, V. K. ; PINTO, M. M. A influência das redes sociais na rotina dos seres humanos. Fasci-Tech - Periódico Eletrônico da FATEC. São Caetano do Sul, São Caetano do Sul, v. 1, n. 5, p. 171 a 179. Out/Dez 2011. 
TOMAÉL, M. I.; ALCARÁ, A. R.; CHIARA, I. G. Das Redes Sociais à Inovação. Ci. Inf. v.34 n. 2 Brasília May/Aug. 2005.

TOMAÉL, M. I.; MARTELETO, R. M. Redes sociais de dois modos: aspectos conceituais. TransInformação, Campinas, 25(3):245-253, set./dez., 2013.

\section{Como referenciar este artigo}

LIMA, Ana Cristina Alves.; LEIVA, Juliene de Cássia.; LEMES, Sebastião de Souza. Viver em rede: uma análise sobre as implicações do uso das mídias sociais por estudantes universitários. Revista on line de Política e Gestão Educacional, Araraquara, v. 21, n. esp. 1, p. 896-912, out./2017. Disponível em: <http://dx.doi.org/10.22633/rpge.v21.n.esp1.out.2017.10459>. E-ISSN:1519-9029.

Submetido em: 10/06/2017

Aprovado em: 25/09/2017 